\title{
USING HYPERSPECTRAL REMOTE SENSING DATA FOR RETRIEVING CANOPY WATER CONTENT
}

\author{
J.G.P.W. Clevers \& L. Kooistra \\ Centre for Geo-Information, Wageningen University, P.O. Box 47, 6700 AA Wageningen, The Netherlands
}

\begin{abstract}
Canopy water content (CWC) is important for understanding functioning of terrestrial ecosystems. Spectral derivatives at the slopes of the $970 \mathrm{~nm}$ and $1200 \mathrm{~nm}$ water absorption features offer good potential as estimators for CWC. An extensively grazed fen meadow is used as test site in this study. Results are compared with simulations with the PROSAIL radiative transfer model. The first derivative at the left slope of the feature at $970 \mathrm{~nm}$ is found to be highly correlated with CWC and the relationship corresponds to the one found with PROSAIL simulations. Use of the derivative over the $940-950 \mathrm{~nm}$ interval is suggested. In order to avoid interference with absorption by atmospheric water vapour, the potential of estimating CWC using the first derivative at the right slope of the $970 \mathrm{~nm}$ absorption feature is recommended. Correlations are a bit lower than those at the left slope, but better than those obtained with water band indices, as shown in previous studies. FieldSpec measurements show that one may use derivatives around the middle of the right slope within the interval between 1015 $\mathrm{nm}$ and $1050 \mathrm{~nm}$.
\end{abstract}

Index Terms - Remote sensing, hyperspectral, canopy water content, water absorption features, spectral derivatives

\section{INTRODUCTION}

Currently one of the main scientific issues is to understand and quantify the impact of global climate change on the Earth system. One of the challenges is the understanding of the role of terrestrial ecosystems in the carbon cycle and the changes they may undergo. The water cycle is one of their most important characteristics. In this respect, the canopy water content is of interest in many applications. In this paper, we focus on retrieving canopy water content from optical remote sensing data, in particular hyperspectral data. Remote sensing techniques provide an integrated signal over the spatial resolution element of the detector. As a result, the canopy water content, being the amount of water per unit ground area, is a variable of interest. However, in radiative transfer (RT) models often the amount of water per unit leaf area, the so-called equivalent water thickness (EWT), is used $[1,2]$. By multiplying the EWT with the leaf area per unit ground area (called the leaf area index, LAI) we get the canopy water content (CWC):

$$
C W C=L A I \times E W T
$$

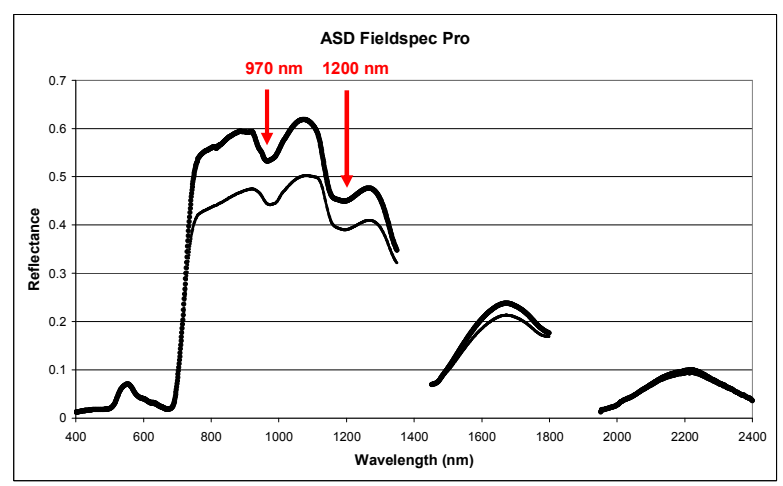

Fig. 1. Example of two spectral signatures of grassland plots measured with the ASD FieldSpec Pro. The position of the water absorption features at $970 \mathrm{~nm}$ and $1200 \mathrm{~nm}$ are indicated.

Fig. 1 shows some spectral measurements on grassland plots performed with an ASD FieldSpec [3]. It shows two water absorption features at approximately $970 \mathrm{~nm}$ and 1200 $\mathrm{nm}$ that are caused by the absorption by $\mathrm{O}-\mathrm{H}$ bonds in liquid canopy water [4]. Accurate measurements at these absorption features in the NIR are feasible with the increasing availability of hyperspectral images. One of the first vegetation indices based on these absorption features was the water band index (WI), defined as the ratio between the reflectance at $900 \mathrm{~nm}$ and the one at $970 \mathrm{~nm}$ [5]:

$$
W I=\frac{R_{900}}{R_{970}}
$$

where $R_{900}$ and $R_{970}$ are the spectral reflectances at $900 \mathrm{~nm}$ and $970 \mathrm{~nm}$, respectively.

Analogously to the normalised difference vegetation index (NDVI), which uses the absorption feature in the red, Gao [6] defined the normalised difference water index (NDWI), which uses the $1200 \mathrm{~nm}$ absorption feature. It is defined as: 


$$
N D W I=\frac{R_{860}-R_{1240}}{R_{860}+R_{1240}},
$$

where $R_{860}$ and $R_{1240}$ are the spectral reflectances at $860 \mathrm{~nm}$ and $1240 \mathrm{~nm}$, respectively.

Danson et al. [7] showed that the first derivative of the reflectance spectrum corresponding to the slopes of the absorption features provides better correlations with leaf water content than those obtained from the direct correlation with reflectance. Rollin \& Milton [8] found moderate correlations between the first derivative at the left slope of both absorption features and CWC for a grassland site in the UK. Clevers et al. [9] applied derivatives in a preliminary study at the field and airborne level. These studies showed that spectral derivatives at the slopes of the $970 \mathrm{~nm}$ and (to a lesser extent) $1200 \mathrm{~nm}$ absorption feature have good potential as predictors of CWC.

Recently, Clevers et al. [3] showed that the first derivative of the reflectance spectrum at wavelengths corresponding to the left slope of the minor water absorption band at $970 \mathrm{~nm}$ was highly correlated with CWC and PROSAIL model simulations showed that it was insensitive to differences in leaf and canopy structure, soil background and illumination and observation geometry. However, these wavelengths are located close to a water vapour absorption band at about $940 \mathrm{~nm}$ [10]. In order to avoid interference with absorption by atmospheric water vapour, the potential of estimating CWC using the first derivative at the right slope of the $970 \mathrm{~nm}$ absorption feature in addition to the one at the left slope is studied in this paper for a dataset acquired in 2008. Results are compared with PROSAIL simulations, using a new version of the PROSPECT model [11].

\section{MATERIAL AND METHODS}

\subsection{Study site}

The study site is an extensively grazed fen meadow acting as a buffer zone around a protected bog ecosystem, located in the Achterhoek area in the Netherlands and forming part of Europe's Natura-2000 ecological network. Ground sampling took place from June $9^{\text {th }}-11^{\text {th }}, 2008.40$ Plots of 3 by $3 \mathrm{~m}$ were randomly distributed over the site. In three corners of each plot subplots of $0.5 \times 0.5 \mathrm{~m}$ were harvested by cutting all above-ground vegetation. Vegetation fresh weight for every subplot was determined after harvesting. After drying for 24 hours at $70^{\circ} \mathrm{C}$, vegetation dry weight and $\mathrm{CWC}$ were determined. Subsequently, the average CWC per plot was calculated.

\subsection{Field Spectroradiometry}

The study site was measured with an ASD FieldSpec on June $9^{\text {th }}$ and $10^{\text {th }}, 2008$. All subplots of all 40 plots were measured before harvesting the biomass. Measurement height above the plot was about $1.5 \mathrm{~m}$ and the instrument field of view was $25^{\circ}$. As a result, at the plot level a circular area of about $0.35 \mathrm{~m}^{2}$ was measured. Calibration was done by using a Spectralon white reference panel.

\subsection{PROSAIL radiative transfer model}

PROSAIL is a combination of the PROSPECT leaf RT model [2] and the SAIL canopy RT model [12], which has been used extensively over the past few years for a variety of applications [13]. At the leaf level, PROSAIL is using leaf chlorophyll content $\left(\mathrm{C}_{\mathrm{ab}}\right)$, equivalent leaf water thickness $\left(\right.$ EWT), leaf structure parameter $(\mathrm{N})$ and leaf dry matter $\left(\mathrm{C}_{\mathrm{m}}\right)$ as inputs. At the canopy level, input parameters are LAI, leaf inclination angle distribution, soil brightness (assuming a constant spectral reflectance for various brightness values), ratio diffuse/direct irradiation, solar zenith angle, view zenith angle and sun-view azimuth angle. It also includes a parameter describing the hot-spot effect [14]. In a previous study, we used an older version of PROSPECT (version 3) simulating leaf reflectance and transmittance at a $5 \mathrm{~nm}$ spectral sampling interval. Recently, version 5 of PROSPECT has been released, performing simulations at a $1 \mathrm{~nm}$ spectral sampling interval and using updated values for the specific absorption coefficients of leaf constituents [11]. Since previous PROSAIL simulations already showed that spectral derivatives at the left and right slope of the $970 \mathrm{~nm}$ absorption feature are strongly correlated with CWC (meaning EWT and LAI) and little influenced by other PROSAIL model input parameters, in this study only EWT and LAI were varied and all other PROSAIL parameters were assumed constant (and representative for the measured grassland site).

\section{RESULTS AND DISCUSSION}

A linear regression of the various spectral derivatives and indices with $\mathrm{CWC}$ was performed. Fig. 2 shows the coefficient of determination $\left(\mathrm{R}^{2}\right)$ between $\mathrm{CWC}$ and the spectral derivatives in the $900-1400 \mathrm{~nm}$ spectral range. Results for this test site confirm previous findings [9]. Best results are obtained for the left slope of the $970 \mathrm{~nm}$ absorption feature (region A). Fig. 3 illustrates the result for the relationship of the derivative over the $940-950 \mathrm{~nm}$ spectral interval with CWC. An $\mathrm{R}^{2}$ of 0.81 is obtained. When using the leave-one-out technique the root mean square error of prediction (RMSEP) is 1.82 ton/ha. However, when using observations from an airborne or spaceborne platform, the atmospheric water vapour absorption band at about $940 \mathrm{~nm}$ might cause problems at this left slope. Moreover, at the left slope the position of the derivative is quite critical. Therefore, we will also look at the right slope. Fig. 2 shows a lower $\mathrm{R}^{2}$ at the right slope (region B). However, the figure is less spiky than at the left 
slope. The right slope of the $970 \mathrm{~nm}$ feature also extends over a larger region. Therefore, the wavelength position is less critical at the right slope and a larger interval can be used. Fig. 2 shows that the interval $1015-1050 \mathrm{~nm}$ might be used. The resulting $R^{2}$ value between derivative and

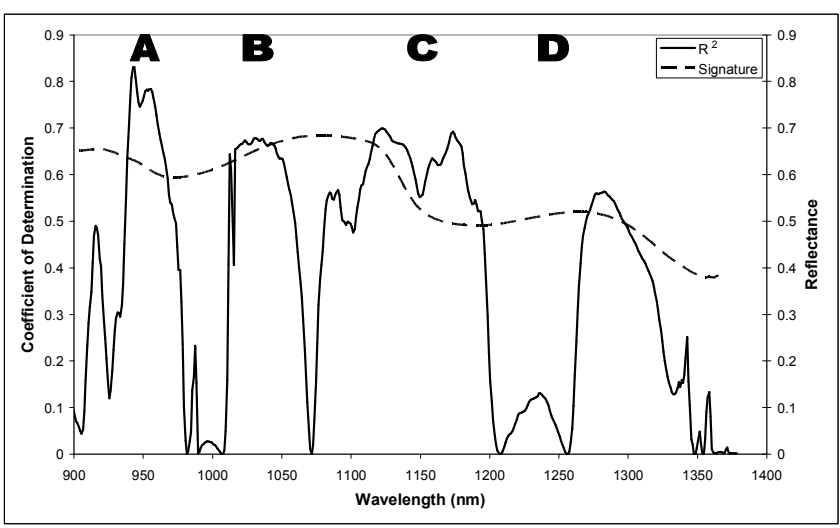

Fig. 2. Coefficients of determination between CWC and first derivative of canopy reflectance measured with the FieldSpec. The dotted line provides an example of a canopy reflectance signature.

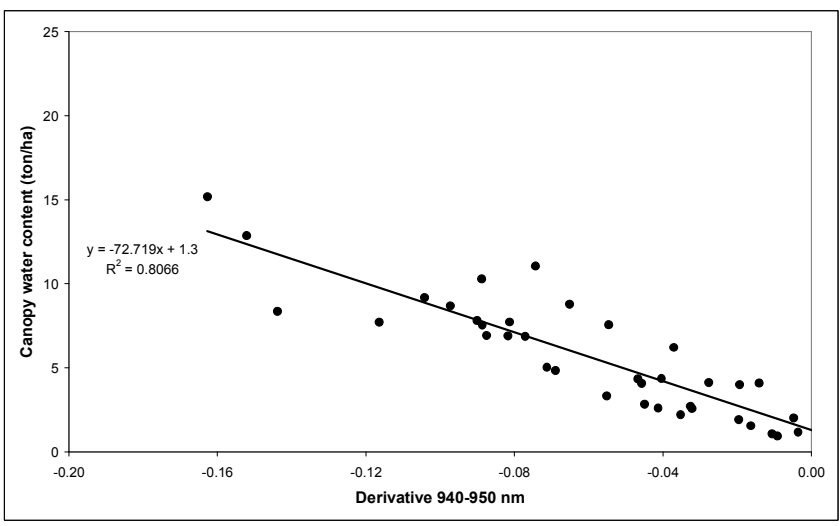

Fig. 3. Relationship between first derivative of FieldSpec canopy reflectance over the interval $940-950 \mathrm{~nm}$ and CWC at the Achterhoek test site in 2008.

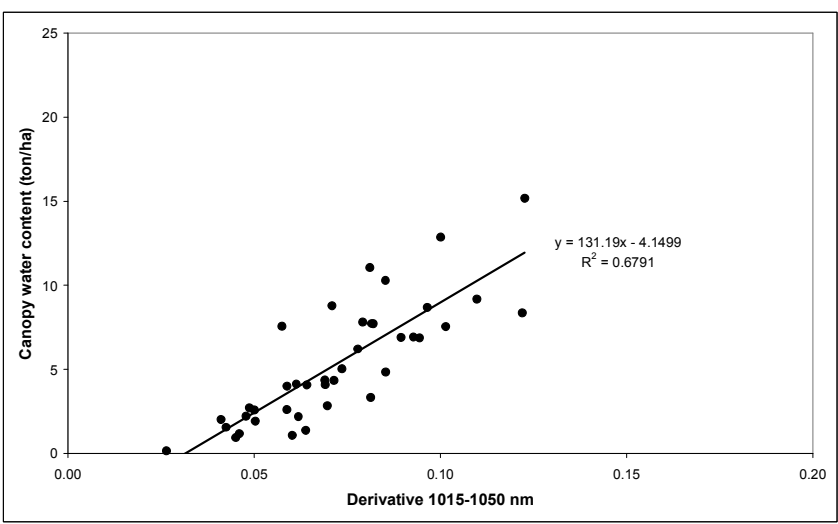

Fig. 4. Relationship between first derivative of FieldSpec canopy reflectance over the interval $1015-1050 \mathrm{~nm}$ and $\mathrm{CWC}$ at the Achterhoek test site in 2008.
CWC appears to be 0.68 (Fig. 4), which is clearly less than the best one found at the left slope. The calculated RMSEP is 2.35 ton/ha using the leave-one-out method.

The experimental results are compared with PROSAIL simulations. For the $940-950 \mathrm{~nm}$ interval the experimental results (Fig. 3) correspond very well with the PROSAIL simulations (Fig. 5). There seems to be a small offset in the experimental data (slope is nearly identical), which can be caused by the assumption of a spectrally constant soil brightness, which is not occurring in reality. For the 1015 $1050 \mathrm{~nm}$ interval the difference between the experimental data and the model simulations is larger (cf. Fig. 4 with Fig. 6). Looking at the signatures with lower coverage, the slope at this interval appears to be significant. This is shown in Fig. 4 by the large offset of the regression line. In addition, the slopes in Figs. 4 and 6 clearly are different.

Results for the water band indices appeared to be somewhat worse when using the PROSAIL simulations. The $\mathrm{R}^{2}$ value for the WI is 0.93 and for the NDWI it is 0.92 . For the Achterhoek data set the $\mathrm{R}^{2}$ values are similar to the best one at the left slope and better than the one at the right slope of the $970 \mathrm{~nm}$ absorption feature $\left(\mathrm{R}^{2}\right.$ for WI is 0.85 and for

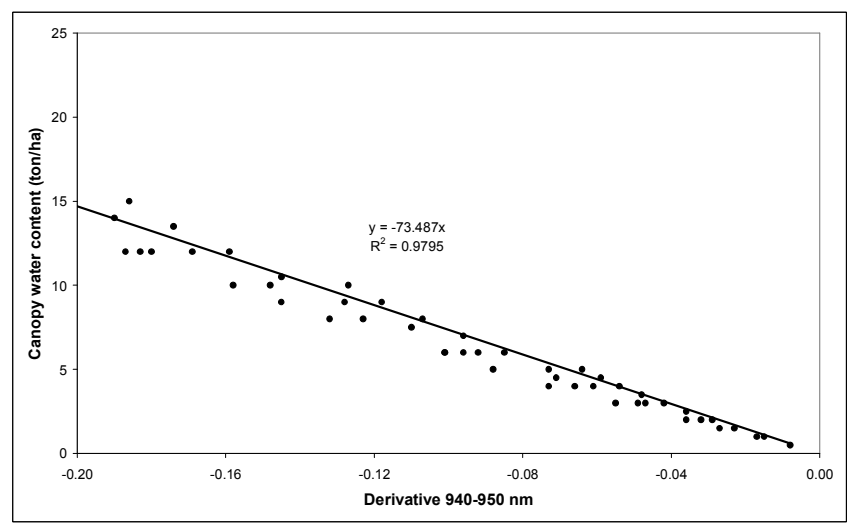

Fig. 5. Relationship between the derivative over the interval $940-$ $950 \mathrm{~nm}$ and CWC as simulated by PROSAIL.

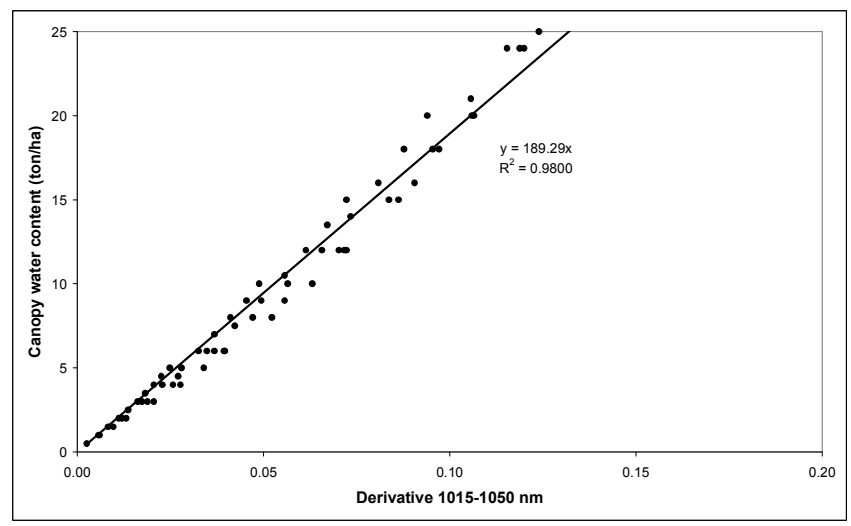

Fig. 6. Relationship between the derivative over the interval 1015 $-1050 \mathrm{~nm}$ and CWC as simulated by PROSAIL. 
NDWI 0.82). For other data sets the water band indices mostly appeared to perform worse than the derivatives [9].

\section{CONCLUSIONS}

Results from this study show that the first derivatives of the reflectance spectrum at the left and the right slope of the 970 $\mathrm{nm}$ absorption feature are linearly correlated with CWC. Correlations are a bit higher at the left slope than at the right slope, but the spectral position of the calculated derivative is much less critical at the right slope. In this study we suggest to use the average derivative over the $1015-1050 \mathrm{~nm}$ interval. Due to the broader interval, this derivative is more robust than the ones used at the left slope.

The experimental regression line between the derivative at the left slope of the $970 \mathrm{~nm}$ absorption feature and CWC is quite similar to the one simulated with the PROSAIL radiative transfer model. Results for the right slope of the $970 \mathrm{~nm}$ feature are deviating from modelling results, but it is noted that most of these differences can be explained by not taking the actual background reflectance into account in the PROSAIL model. Further research is still required.

For drought detection in vegetation or for mapping fire susceptibility the water concentration (or EWT) is more important than the total content. This quantity can be estimated by dividing the water content by the LAI. So, an independent estimate of LAI is needed, which, e.g., can be obtained by using the weighted difference vegetation index WDVI [15].

\section{ACKNOWLEDGEMENT}

This work has been supported by the European Community's Marie Curie Research Training Networks Programme under contract MRTN-CT-2006-035927, Hyperspectral Imaging Network (HYPER-I-NET).

\section{REFERENCES}

[1] E. R. Hunt Jr. and B. N. Rock, "Detection of changes in leaf water content using near- and middle-infrared reflectances," Remote Sensing of Environment, vol. 30, pp. 43-54, 1989.

[2] S. Jacquemoud and F. Baret, "Prospect - a model of leaf optical properties spectra," Remote Sensing of Environment, vol. 34, pp. 75-91, 1990.

[3] J. G. P. W. Clevers, L. Kooistra, and M. E. Schaepman, "Canopy water content retrieval from hyperspectral remote sensing," presented at 10th International Symposium on Physical Measurements and Signatures in Remote Sensing, Davos, Switserland, 2007.

[4] P. J. Curran, "Remote sensing of foliar chemistry," Remote Sensing of Environment, vol. 30, pp. 271-278, 1989.
[5] J. Peñuelas, J. Piñol, R. Ogaya, and I. Filella, "Estimation of plant water concentration by the reflectance water index WI (R900/R970)," International Journal of Remote Sensing, vol. 18, pp. 2869-2875, 1997.

[6] B. C. Gao, "NDWI - A normalized difference water index for remote sensing of vegetation liquid water from space," Remote Sensing of Environment, vol. 58, pp. 257-266, 1996.

[7] F. M. Danson, M. D. Steven, T. J. Malthus, and J. A. Clark, "High-spectral resolution data for determining leaf water content," International Journal of Remote Sensing, vol. 13, pp. 461-470, 1992.

[8] E. M. Rollin and E. J. Milton, "Processing of high spectral resolution reflectance data for the retrieval of canopy water content information," Remote Sensing of Environment, vol. 65, pp. 86-92, 1998.

[9] J. G. P. W. Clevers, L. Kooistra, and M. E. Schaepman, "Using spectral information from the NIR water absorption features for the retrieval of canopy water content," International Journal of Applied Earth Observation and Geoinformation, vol. 10, pp. 388397, 2008.

[10] B. C. Gao and A. F. H. Goetz, "Column atmospheric water vapor and vegetation liquid water retrievals from airborne imaging spectrometer data," Journal of Geophysical Research, vol. 95, pp. 3549-3564, 1990.

[11] J. B. Feret, C. François, G. P. Asner, A. A. Gitelson, R. E. Martin, L. P. R. Bidel, S. L. Ustin, G. le Maire, and S. Jacquemoud, "PROSPECT-4 and 5: Advances in the leaf optical properties model separating photosynthetic pigments," Remote Sensing of Environment, vol. 112, pp. 3030-3043, 2008.

[12] W. Verhoef, "Light scattering by leaf layers with application to canopy reflectance modeling: the SAIL model," Remote Sensing of Environment, vol. 16, pp. 125-141, 1984.

[13] S. Jacquemoud, P. J. Zarco-Tejada, W. Verhoef, G. P. Asner, S. L. Ustin, F. Baret, and C. François, "PROSPECT+SAIL: 15 Years of use for land surface characterization," presented at International Geoscience and Remote Sensing Symposium (IGARSS), art. no. 4241663, 2006.

[14] A. Kuusk, "The angular-distribution of reflectance and vegetation indexes in barley and clover canopies," Remote Sensing of Environment, vol. 37, pp. 143-151, 1991.

[15] J. G. P. W. Clevers, "The application of a weighted infraredred vegetation index for estimating Leaf Area Index by correcting for soil moisture," Remote Sensing of Environment, vol. 29, pp. 25-37, 1989. 